\title{
СПЕЦИФИЧЕСКАЯ ДИСТИНКТИВНОСТЬ В ИНТЕРНЕТ-СЛЕНГЕ СОВРЕМЕННОЙ НЕМЕЦКОЙ МОЛОДЁЖИ
}

\section{SPECIFIC DISTINCTIVENESS IN THE INTERNET SLANG OF MODERN GERMAN YOUTH}

O. Litvjak

Summary: The article offers to consider the slang expressions of modern German-speaking youth, as well as their explanations. The concept and meaning of slang in the language system, as well as differences from jargon, are considered. During the work on the article, several main types of abbreviations used in Internet correspondence were identified, as well as the features and areas of use of slang vocabulary of young people.

Keywords: slang, jargon, youth, internet, social networks, communication, abbreviations, abbreviations, correspondence, vocabulary.
Я зык - это материал, с помощью которого мы общаемся, мыслим и чувствуем. Язык - это динамичная система, которая всё время меняется вместе с развитием нашего общества. Исследование и анализ разговорной лексики, также языка является значимой задачей современной лингвистики. Так как роль Интернета, значительно взросла в современном обществе, изучение особенностей молодежного сленга становиться всё более актуальным. В результате мы можем наблюдать интенсивное изменение лексики на данном уровне. Необходимо изучать разговорную лексику на различных интернет-платформах, анализировать их тенденции, тем более что речь молодежи достаточно стилистически динамичны и многообразны.

Немецкий язык на современном этапе своего развития определяется как целая концепция, которую образует огромное число взаимосвязанных подсистем. К ее структуре относятся разнообразные диалекты, арго, жаргоны, сленги представителей различных профессий, социальных и возрастных групп. Но они все без исключения имеют более или менее интенсивное воздействие на процессы, происходящие в общенациональном немецком языке, определяя его особенности и тенденции развития. Следовательно, одной из важных составляющих современного общенационального немецкого языка является молодежный сленг. Он является довольно неординарным явлением, представляющим собой отдельную языковую подсистему, которая тем не менее взаимозависима с другими языковыми подсистемами.

Цель данной статьи проанализировать такое явле-
Литвяк Олеся Валерьевна

К.филол.н., дочент, Крымский инженерно-педагогический университет имени Февзи Якубова, г. Симферополь ole.litviak@yandex.ru

Аннотация: В статье предлагается к рассмотрению сленговые выражения современной немецкоязычной молодежи, а также их объяснения. Рассматриваются понятие и значение сленга в языковой системе, а также отличия от жаргона. В ходе работы над статьей были выделены несколько основных видов сокращений, используемых в интернет-переписках, а особенности и сферы использования сленговой лексики молодежи.

Ключевые слова: сленг, жаргон, молодежь, интернет, социальны сети, коммуникация, сокращения, аббревиатура, переписка, лексика.

ние языка, как «молодежный сленг», исследовать историю его происхождения и классификацию, указать место сленгового лексики в речи немецкой молодежи.

Материалом для анализа послужил материал интернет-переписок немецкой молодежи. Теоретической основой для написания данной научной статьи послужили работы отечественных исследователей таких, как Э.М. Береговской, Е.И. Васильева, М.К. Седова, Я.О. Белова, С.В. Сырескина.

Многие исследования немецких социологов показали, что в 90-е годы двадцатого века в Германии особую значимость приобрел молодежный образ жизни, который нашел свое языковое представление именно в молодежном сленге. Результатом усиления роли молодежи в жизни немецкого общества является укрепление позиции молодежного сленга в языковой системе в целом. Поэтому особенности речевого поведения немецкой молодежи изучаются уже достаточно длительное время, а молодежный сленг стал популярным объектом лингвистических исследований на материале разных языков.

Жаргонные, неформальные, нестандартные слова и фразы, как правило, короче, чем выражения обычной разговорной речи, и, как правило, формируются творческими, часто остроумными сопоставлениями слов или образов. Однако сленг можно противопоставить жаргону и арго, но границы, отделяющие эти категории от сленга, сильно размыты, и некоторые авторы используют термины «арго» и «жаргон» в общем смысле. 
Сленг, как правило, берет свое начало в субкультурах внутри общества. Профессиональные группы являются одними из создателей как жаргона, так и сленга; другие группы, создающие сленг, включают подростков, расовые меньшинства, блогеров, спортивные группы, преступников и даже религиозные конфессии. Жаргонные выражения часто отражают отношение и ценности членов группы. Таким образом, они могут способствовать формированию чувства групповой идентичности и могут передавать слушателю информацию о прошлом говорящего. Однако, прежде чем подходящее выражение станет жаргоном, оно должно быть широко распространено членами субкультуры. На этом этапе сленг и жаргон сильно пересекаются. Если субкультура имеет достаточный контакт с господствующей культурой, ее фигуры речи становятся жаргонными выражениями, известными всему обществу. Жаргонное выражение могут внезапно стать широко используемым и так же быстро устаревшим. Оно может быть принято как стандартная речь, либо в своем первоначальном сленговом значении, либо с измененным, возможно, укрощенным значением. Некоторые выражения сохранились на протяжении веков в качестве сленга. В 20 веке средства массовой информации и быстрые путешествия ускорили как распространение, так и упадок жаргонных терминов

В некоторых случаях сленг может дать необходимое название объекту или действию, или он может предложить эмоции или сатирическую отсылку. Он может содержать эвфемизмы, и он может позволить своему пользователю создать шоковый эффект, используя острое жаргонное выражение в неожиданном контексте. Сленг является одним из средств, с помощью которых языки меняются и обновляются, именно им молодежь обогащают свою повседневную речь. Хотя он приобрел свою респектабельность только в 20 веке, в прошлом его часто громко осуждали как вульгарный. Сленг появляется во все времена и на всех языках. Среди западных языков английский, французский, испанский, итальянский, немецкий, идиш, румынский и цыганский (цыганский) особенно богаты сленгом.

Сленг развивается, меняется очень быстро. Это образование, которое может как легко образоваться, так и исчезнуть. Эти все изменения происходят для упрощения устной речи и ее понимания. Сленг - очень живое и динамичное образование. Его используют в различных сферах общественной жизни. Это важная часть языка, которая помогает поддерживать его «живым».

Но весомую роль играет так же принадлежность к социальной группе, пространственные и временные ограничения. Так доктор филологических наук Э.М. Береговской считает, что он очень широко распространен в кругах городской учащейся молодежи. Э.М. Берговская в своей статье «Молодежный сленг: формирование и функционирование» подчеркивает четыре главные черты молодежного сленга:

1. Депрециативность - критическое, ироническое отношение к «миру взрослых», устоявшимся ценностям.

2. Метафоричтичность - язык отличается высоким уровнем словотворчества, образностью.

3. Доминирование репрезентативной функции доминирование действия языковых априори.

4. Людическая направленность - некая размытость границ [1].

Сегодня Интернет служит не только эффективным средством коммуникации в целом, но и средством установления первичного контакта между его пользователями, в том числе географически удаленными друг от друга. Значение интернета возрастает во всех сферах человеческой жизни, включая не только науку и образование, но и экономику, развлечения и хобби. Таким образом главным изобретением последних лет является коммуникация с помощью компьютерных технологий, которую можно описать как общение между людьми благодаря разнообразным цифровым технологиям. Интернет привлекает всех новых пользователей, требует не только навыков работы в Интернете, но и владения языком, на котором представлено большинство ресурсов. Огромное количество пользователей видят в Интернете не только средство общения, но и возможность высказать свои мысли, описать, что с ними произошло, поделиться опытом.

Интернет стал одним из источников влияния на немецкий язык в последнее время, и наряду с присвоением существующего словарного запаса, он породил много новых слов и фраз.

Однако иногда язык, используемый в онлайн-пространствах, проникает в другие языковые пространства, такие как разговор лицом к лицу. Это связано с тем, что наша деятельность в Интернете может быть компонентом нашей идентичности, и язык, связанный с этой деятельностью, может проникнуть в другие места. Например, если кто-то проводит большую часть своего времени в Интернете, играя в онлайн-игры, и идентифицирует себя как «геймер», то знаковый язык из сообщества онлайн-игр может проникнуть в речь, которую этот человек использует в другое время.

Сленг можно подразделить на некоторые виды, например:

- «Рифмующийся сленг», он часто используется среди молодежи, многие употребляют его также и в повседневной жизни, не замечая этого, а люди старшего зачастую не могут понять эти.

- «Повседневный сленг», зависит от контекста, в котором употребляется. Например, если человек о 
чем-то сильно беспокоится. Тогда, чтобы поддержать человека и отпустить ситуацию можно сказать: «Mach dir keinen Kopf» (не парься).

- «Мобильный сленг», основан на так называемой функции «Т9». Молодежь, при наборе сообщения, выбирают первое слово, предложенное этой программой. Так, например, подростки Великобритании любят сокращения в разговорной речи и эти элементы тоже можно считать сленгами. Например: gonna - going to, wanna - want to, yeah - yes, U - you, ur- your, idk - don't know, Cause - because [3].

Проблема специфики интернет-сленга немецкой молодежи впервые коснулись в 2001 году в Вуппертале на международной конференции «Jugendsprachen - Spiegel der Zeit» («Молодежные языки - зеркало времени»), где известные исследователи немецкого молодежного жаргона Я. Андроутсопоулос и М. Рейнке представили свои доклады, в которых рассмотрели различные стили сообщений молодежи и описывают особенности речевого поведения молодых людей как интернет-пользователей. Также эту тему коснулись, и авторы статьи «Молодежь пишет в Интернете» Г. Клейнберга и К. Шпигеля, на множествах примерах демонстрируют грамматические и орфографические нарушения во время виртуального общения молодых пользователей Интернета.

Рассматривая особенности неформального языка общения немецких пользователей Сети, стоит заметить, что неотделимым атрибутом сообщений современной молодежи, все значительней следуют принципу «как слышу, как говорю, так и пишу», таким образом появляются разного рода аббревиатуры и укороченные версии нормативной или сленговой лексики. Данная направленность основывается на стремлении молодых людей к экономии языковых средств и в некоторой степени к созданию эмоционально-экспрессивных единиц, популярных только ограниченному кругу лиц или лишь людям по переписке.

Немецкий стиль текстовых сообщений со временем немного изменился. Большей известностью у пользователей сетевой аудитории, и о данном говорит частотность их использования в самых всевозможных обстановках, употребляют, например, именуемые инициальные аббревиатуры - сокращения, образованные из первых букв, входящих в начальное словосочетание и произносимых при чтении в сокращенной, а не в абсолютной форме, такое явления можно назвать Kurzdeutsch (короткий немецкий). Это просто показывает, что теперь пользователи используют сокращенные выражения в текстовых сообщениях вместо полных предложений. Поэтому они исключают глаголы или местоимения, которые не всегда необходимы, и это может вызвать недоумения у стар- шего поколения или у людей, которые только начали изучение немецкого языка [2].

Есть множество примеров интернет-сокращения, которые используют в немецкоязычной переписке:

- BD (Bis dann), что переводится «Увидимся», используется при прощании с намерением встретиться снова позже в тот же день.

- Liebe Grüßе буквально переводится как «прекрасные приветствия», но на самом деле означает «с наилучшими пожеланиями». Это сокращение подходит для любой сетевой переписки. Варианты включают «Beste Grüßе» (лучшие приветствия) и «Viele Grüße» (много приветствий), часто сокращенные как «BG» и «VG».

- Mmm, это вовсе не звук, который означает "звучит восхитительно", но вместо этого он означает meiner Meinung nach (на мой взгляд). Что-то вроде немецкого эквивалента IMHO: “По моему скромному мнению."

- QK, образовано от слова «Quatschkopf», переводится буквально как "глупая голова", обычно используется в беззаботной, шутливой манере, чтобы означать что-то вроде «птичьего мозга», в случае, когда кто-то, ну, говорил глупости. С другой стороны, «Quatschen» означает "болтовня" о всевозможных вещах-не обязательно бессмысленных.

- $\mathrm{SfH}$, от словосочетания «Schluss für Heute» буквально означает «закрыть на сегодня», но на самом деле означает «на сегодня достаточно». Schluss machen довольно часто используется для обозначения "закончить" или "прекратить", но может иметь более серьезное значение, сигнализируя о разрыве отношений [6].

- WE, образовано «WochenEnde» и это скоращения для "выходных." Использование аббревиатуры предлагает быстрый способ спросить, что человек собирается делать в свободное время в выходные дни.

— Vlt. или Vllt, слово «vielleicht» часто используется в немецком языке. Но, если само слово напечатать на клавиатуре, и в девяти случаях из десяти будет сделана ошибка. Поэтому вместо этого все просто набирают «vlt».

- AFK и BTK, от выражение «Weg von der Tastatur / Zurück an der Tastatur». Часто используется геймерами и в компьютерной сцене. Часто геймеры общаются со своими товарищами по команде, быстро заходят в ванную и дают им понять, что они отошли от клавиатуры или вернулись к клавиатуре.

- HDF расшифровывается как «Halt die/deine Fresse!» (замолчи!). В настоящее время неприятные высказывания и плохие слова распространены в социальных сетях, поэтому можно наткнуться на человека, который не согласен с чьим-то мнением.[4] 
Следовательно, аббревиатуры можно разделить на несколько видов:

1. Аббревиатуры с использованием строчных букв:

- akla - Alles klar? Bсе понятно (ясно)?

- www - Wir werden warten - Будем ждать;

- bd - brauche dich - Ты мне нужен / ты нужна мне;

- braduhi? - Brauchst du Hilfe? - Тебе нужная помощь?

— ild - Ich liebe dich, сокращение от «Я тебя люблю».

— vd! - Ich vermisse dich! - Я по тебе скучаю! [4]

2. Аббревиатуры с использованием прописных букв

- HAHU - Habe Hunger - Я голодный;

- HASE - Habe Sehnsucht - Я грущу;

- JON - Jetzt oder nie - Сейчас или никогда;

- KV - kannst vergessen - Забудь;

- RUMIAN - Ruf mich an - Позвони мне;

- DN! - Du nervst! - Ты меня раздражаешь! [4]

3. Аббревиатуры с использованием букв и цифр:

- ko30mispa - komme 30 Minuten später - Приду на 30 минут позже

- gn8 - Gute Nacht - Спокойной ночи!

- Q8 - Komme um sechs Uhr - Приду в 8 часов

Так в молодежном сленге наблюдается наиболее полное отражение изменений, происходящих в обществе, и выражения отношения молодежи к этим изменениям.

«Alter Schwede! Was hast du gemacht?», «Man, das Essen war so geil!» или же «Der Typ is Irre!» [5] - такие высказывания мы можем услышать лишь из уст молодежи. Именно из-за них старшее поколение часто ломает себе головы, пытаясь догадаться, а иногда почти расшифровать содержание высказывания.

Манера говорить, что присуща молодежи, была и остается феноменом. Она целиком и полностью зависит от времени и меняется вместе с новыми тенденциям. Ее лексические единицы могут быть настолько остроумными и образными, что взрослые иногда заимствуют отдельные слова в свой лексикон.

Рассмотрим некоторые слова, которые молодые люди часто используют в повседневной жизни:

- «Moin», это сокращение фразы «Guten Morgen» или «Доброе утро» в некоторых частях северной Германии. Но многие люди приняли это как способ сказать «Привет!» на немецком сленге, независимо от того, сколько сейчас времени.

- «Krass». Чтобы заменить несколько слов для описания одной вещи, в немецком существует для этого одно слово, чтобы попытаться описать все. «Krass»-одно из таких слов, потому что оно может быть использовано для описания как хороших, так и плохих эмоций в равной мере. Например, можно использовать его для описания чего-то: «Das Essen hier is krass! Ich liebe es», (Еда здесь от- личная! Мне это нравится), но также слово может быть использован в качестве ответа на что-то негативное, например «Das Restaurant is krass, ich finde es immer so dreckig» (Этот ресторан ужасен, он всегда такой грязный).

- «Hammer» - это инструмент, который вы используете, чтобы забивать гвозди в дерево. Но немцы также используют его для описания того, что что-то классное или выдающееся. Его можно использовать просто как «Hammer!», чтобы ответить на что-то классное. Например, «Alter, es war der Hammer!», что означает «Приятель, это было безумно!».

— «Jein» - это смесь слов «Ја» и «Nein». Немцы часто используют это слово, чтобы описать, когда что-то не ясно или они еще не приняли решение. Так, например, на вопрос: «Seid ihr jetzt in einer Beziehung?» (Вы сейчас в отношениях?» можно «Јеin» (Да и нет. Может быть. Кто знает!?).

- «Mensch» по-немецки означает «человек», но это также может быть способ сказать «О боже!». Часто используется, чтобы показать недовольство кемто или чем-то.

— «Verarschen»- слово, чтобы выразить, когда кто-то дурачит вас или издевается. Это можно использовать в легкомысленном ключе, например, «lch verarsche dich nur» можно сказать, как «я просто шучу с вами». Или же наоборот, когда кто-то делает что-то плохое, можно сказать: «Willst du mich verarschen?» (Вы пытаетесь поссориться?)[5].

Поэтому сленг является одним из источников обогащения современного немецкого языка. Молодежи свойственны фантазия и креативность, которые они успешно используют для создания новых интересных слов, то есть они совершенствуют старый и несколько скупой, по их мнению, лексический состав немецкого языка. Так возникает их собственный язык, который взрослые довольно трудно или иногда вообще не понимают. Именно поэтому молодежный сленг подвергается многочисленной критике.

Что для молодежи является естественным и обычным, часто шокирует взрослых. Молодежь перефразирует на свой лад слова из профессиональных сленгов, диалектов, иностранных языков и различных социолектов в том случае, когда в общепринятой системе языка нет такого языкового средства, которое бы наиболее полно выражало их мнение.

Стоит отметить, что большое количество английских сокращений и заимствований, также отразились на лексику современной немецкой молодежи. Английский язык является самым распространённым в Интернете, а так как многочисленные компьютерные технологии, социальные сети и новые тенденции появляются в основ- 
ном Соединенных Штатах Америки, то англо-американские лексика интернет - общения, часто заимствуются вместе с новыми явлениями и являются терминологическими определениями, например online, Chat, E-Mail, Hacker Cyberspace, Server, Provider, Browser, Homepage, downloaden и другие. Многие из этих слов считаются интернациональными, так и словообразовательные модели, а немецкий язык интернет - общения заимствует непроизводные и производные единицы, а также словосочетания. Такие слова как Byte, Chat, Click, File, Freak, Icon, Nerd являются непроизводными англо - американизмов. В свою очередь непроизводные англо - американизмы воспринимаются носителями немецкого языка так же, как и в исходном языке, как корневые слова.

К производным заимствованным единицам можно отнести англо-американизмы, что были образованны способом аффиксации, словосложения и аббревиации:

- префиксальные заимствования: downloaden, Telelearning, Teleworking, Update, upgraden, uploaden и др.;

- суффиксальные заимствования: Browser, Provider, Scanner, Server, Surfer, User и др.;

- заимствования-композиты:

1.двухкомпонентные Bookmark, Chatroom, Cyberspace;

2.трёхкомпонентные Computer Based-Learning, Computer-Based-Training, One-Click-Shopping, Data-Dollar-Highway;

3. четырёхкомпонентные i-net-software, i-netwebdesign;

- заимствования-аббревиатуры:

1. инициальные сокращения AR (Augmented Reality), HTML (Hyper Text Markup Language);

2. буквенно-цифровые аббревиатуры $2 \mathrm{U}$ (to уоu), f2f (face to face),

3. сложносокращённые слова Digicash, E-Banking, E-Society, iHomepage.

В немецкоязычных чатах также не редко можно встретить заимствования из английского языка типа: D.I.Y. - Do it yourself; LOL - Laughing out loud CU! - See you! CYA - See you all.

С внедрением аббревиатур в современные технологии ежедневное общение может сократить количество слов и символов, используемых для точного ведения раз- говора. Это означает, что Лексический уровень требует особого внимания, так как общеупотребительными и более распространенными в реальной речи становятся единицы именно лексического уровня: акронимы, созданные в интернете (LOL, IMHO, ASAP), неологизмы, активное употребление которых происходит не только в областях, имеющих отношение к компьютеру. По мере того как общение становится более быстрым и делает больше людей более доступными, чем когда-либо прежде, ответственность и ожидания, связанные с таким общением, возрастают. Язык постоянно развивается и всегда развивался. Дело в том, что Интернет трансформируют то, как воспринимается и используется язык. Его влияние на использование языка проявляется в количестве ежедневных коммуникаций, количестве людей, с которыми люди общаются, характере и стиле общения.

Немецкий язык, как и многие другие языки, развивается и обогащается новые слова и выражения. Есть множество лексики, которая выходит за общепринятые рамки языковых норм и используется обычными пользователями для самовыражения- сленг. Основой немецкого сленга является молодежный сленг.

Немецкий молодежный сленг - это эмоционально окрашенная речь, которая используется для идентификации конкретной возрастной группы, в частности молодежи, и отражает ее мировоззрение и ценностные ориентиры, и выполняет функции идентификации, консолидации, скрытого престижа. Основными признаками молодежного сленга является лаконичность, сосредоточенность на реалиях мира молодежи, обилие вульгаризмов, семантический юмор (особенно ценится игра слов). Лексика сленга молодых людей отражает сферы занятий и интересы его носителей. Основными источниками пополнения немецкого молодежного сленга являются иноязычные заимствования, среди которых преобладают английские.

Будущее всецело зависит от молодёжи, которая наполняет язык особыми отличительными особенностями, создавая отдельную ветвь языка, которая называется «сленг». Поэтому в период быстро видоизменяющегося языка очень важно успевать за тем, как строится его новая история. Понятие и осознание того, что именно язык является главным связующим звеном между поколениями, позволяет сблизить разные эпохи.

\section{ЛИТЕРАТУРА}

1. Васильева, Е.И. Тенденции интернет-сленга немецкоязычной аудитории в 2017 году / Е.И. Васильева. — [Текст] // Современная филология: материалы VI Междунар. науч. конф. (г. Казань, март 2018 г.). — Казань: Молодой ученый, 2018. — C. 15-18. — Режим доступа: https://moluch.ru/conf/phil/ archive/259/13798/ (дата обращения: 12.06.2021)

2. Россихина Мария Юрьевна, Быков Андрей Андреевич Специфика интернет-сленга немецкоязычной молодежи — [Текст] // Вестник Северного (Арктического) федерального университета. Серия: Гуманитарные и социальные науки. 2016. №4. - Режим доступа: https://cyberleninka.ru/article/n/spetsifika- 
internet-slenga-nemetskoyazychnoy-molodezhi (дата обращения: 13.06.2021)

3. Седова, М.К. Молодёжный сленг в современном английском языке / М.К. Седова, Я.О. Белова, С.В. Сырескина. — [Текст] // Филология и лингвистика. — 2016. — № 2 (4). — C. 34-36. — Режим доступа: https://moluch.ru/th/6/archive/33/1057/ (дата обращения: 12.06.2021).

4. Complete Guide of German Slang for Texting and Internet // GermanPod101.com [Electronic source]/URL: https://www.germanpod101.com/blog/2019/07/23/ german-text-slang/ (access date: 12.06.2021)

5. Everyday German Slang Words (So You Sound Like A Native) // Fluent in 3 months with BENNY the Irish polyglot [Electronic source]/URL: https://www. fluentin3months.com/german-slang/ (access date: 12.06.2021)

6. The Must-have Guide to German Internet Slang for Modern Learners // FluentU. [Electronic source]/URL: https://www.fluentu.com/blog/german/germaninternet-slang/ (access date: 12.06.2021)

(c) Литвяк Олеся Валерьевна (ole.litviak@yandex.ru).

Журнал «Современная наука: актуальные проблемы теории и практики»

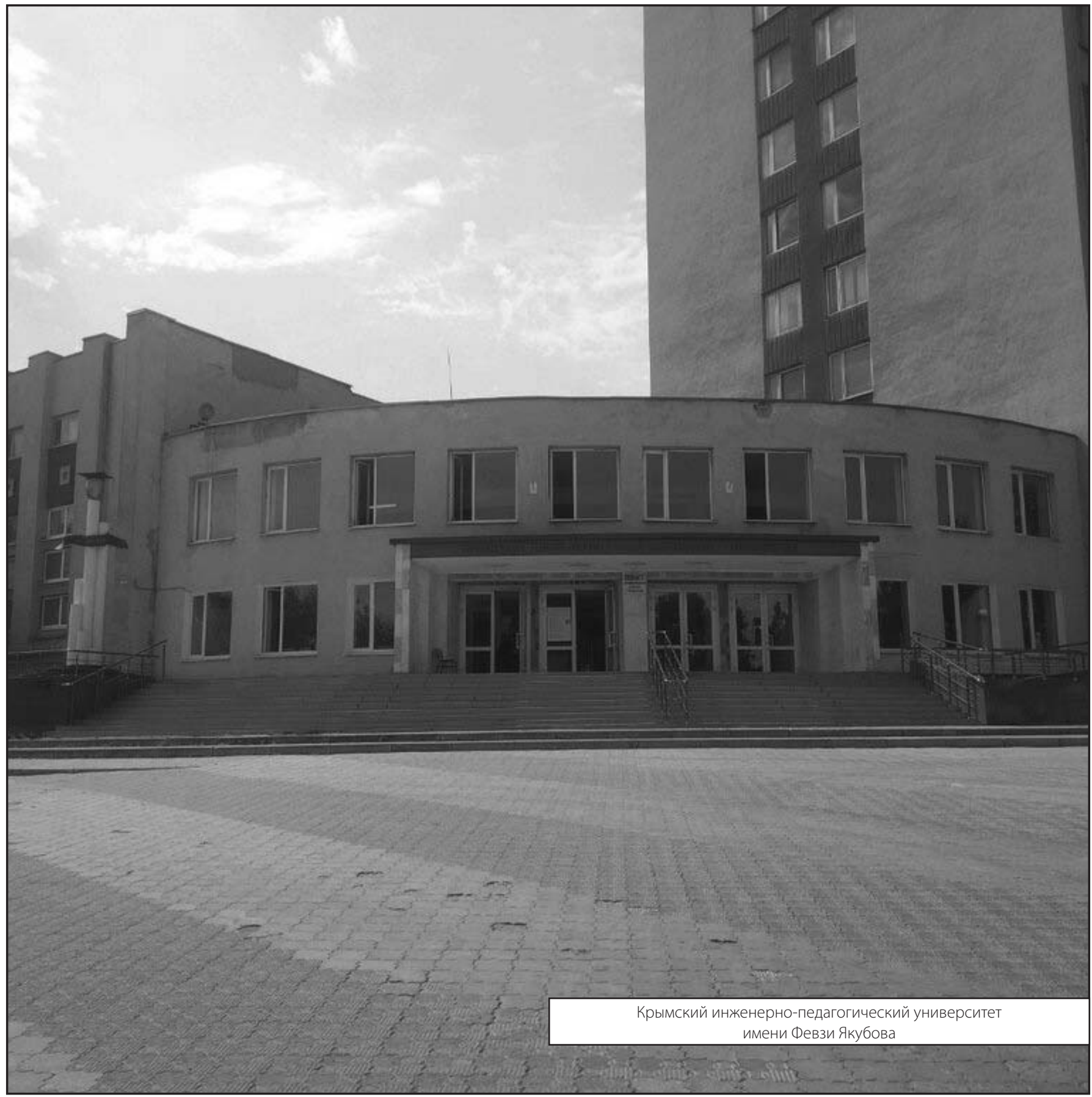

